\title{
Identification of foliage plants Heuchera based on electrochemical profile of active molecules
}

\author{
Yuhong Zheng ${ }^{1, *}$, Xiaolong $\mathrm{Li}^{2}$, Fugui $\mathrm{Han}^{1}, \mathrm{Li} \mathrm{Fu}^{2, *}$ and Jinbo Sun ${ }^{3}$ \\ ${ }^{1}$ Institute of Botany, Jiangsu Province \& Chinese Academy of Sciences (Nanjing Botanical Garden \\ Mem. Sun Yat-Sen), Nanjing 210014, PR. China \\ ${ }^{2}$ Key Laboratory of Novel Materials for Sensor of Zhejiang Province, College of Materials and \\ Environmental Engineering, Hangzhou Dianzi University, Hangzhou, 310018, PR. China \\ ${ }^{3}$ Shuyang Jindi Landscaping Engineering Co. Ltd, Shuyang 223600, PR. China \\ "E-mail: zhengyuhong@ cnbg.net, fuli@ @du.edu.cn
}

Received: 3 August 2021 / Accepted: 13 September 2021 / Published: 10 October 2021

\begin{abstract}
An electrochemical profile of plant tissue can reflect the genetic differences among different plants. In this work, the electrochemical profiles were used to identify 12 Heuchera cultivars. Leaf extracts of Heuchera 'Rio', Heuchera 'Tapestry', Heuchera 'Caramel', Heuchera 'Paris', Heuchera 'Huashiliu', Heuchera 'Cherry Cola', Heuchera 'Tiramisu', Heuchera 'Obsidian', Heuchera 'Midnight Ruffles', Heuchera 'Electra', Heuchera 'Georgia Peach' and Heuchera 'Red Wine' were prepared for recording the electrochemical profiles. These electrochemical profiles were used to construct different pattern recognition strategies and to identify cultivars. The identification of patterns was more accurate than that of individual electrochemical profiles.
\end{abstract}

Keywords: Electroanalysis; Leaf extract; Plant identification; Heuchera; Biometrics

\section{FULL TEXT}

(C) 2021 The Authors. Published by ESG (www.electrochemsci.org). This article is an open access article distributed under the terms and conditions of the Creative Commons Attribution license (http://creativecommons.org/licenses/by/4.0/). 